\title{
Response to Growth Hormone Treatment and Final Height in Noonan Syndrome in a Large Cohort of Patients in the KIGS Database
}

\author{
R. Raaijmakers ${ }^{1}$, C. Noordam ${ }^{1}$, G. Karagiannis ${ }^{2}$, J.W. Gregory ${ }^{3}$, N.T. Hertel ${ }^{4}$, 1. Sipilä ${ }^{5}$ and B.J. Otten ${ }^{1}$ \\ 'Radboud University Nijmegen Medical Centre, Metabolic and Endocrine Disorders, Nijmegen, \\ The Netherlands, ${ }^{2}$ Pfizer Endocrine Care, KIGS Medical Outcomes, Stockholm, Sweden, \\ ${ }^{3}$ Wales College of Medicine, Cardiff University, Cardiff, Wales, UK, \\ ${ }^{4}$ Odense University Hospital, Paediatric Department, Odense, Denmark and \\ ${ }^{5}$ Children's Hospital, Department of Paediatric Endocrinology, Helsinki, Finland
}

\begin{abstract}
Background: Noonan syndrome (NS) is an autosomal dominant inherited disease, characterized by a distinctive facial appearance, congenital heart defects, and short stature. Treatment with growth hormone (GH) is an option to enhance height, but long-term effects are still unclear.

Patients and Methods: A cohort of 402 patients (269 males, 133 females), mean age 9.7 years at start with GH, was studied within the KIGS International growth database with respect to long-term response to $\mathrm{GH}$ therapy and final height after GH therapy.

Results: At the start of GH therapy median height was -2.61 SDS (Tanner 1966 standards). Seventy-three patients who were followed longitudinally for 3 years had an increment in height SDS (Ht SDS) over the first 3 successive years of $0.54,0.13$ and 0.13 , respectively. Twenty-four patients had reached their final height after 4-12 years of GH treatment. Their Ht SDS increased from a median of -3.28 to a median of -2.41 at final height.

Conclusion: This group of patients with NS showed an early response to GH treatment, with an attenuation of this effect thereafter. At final height the median increment of final height was
\end{abstract}

Reprint address:

B.J. Otten

UMC St Radboud

Metabolic and endocrine disorders 833

P.O. Box 9101

6500 HB Nijmegen, The Netherlands

e-mail: b.otten@cukz.umcn.nl
0.61 SDS according to Tanner standards and 0.97 SDS according to Noonan standards. No serious side effects were reported.

\section{KEY WORDS}

Noonan syndrome, growth hormone, longitudinal growth, final height

\section{INTRODUCTION}

Noonan syndrome (NS) is a relatively common multiple congenital anomaly syndrome, first described in 1963 by Noonan and Emke', with an incidence of one per 1,000 live births ${ }^{2,3}$. The inheritance of NS is autosomal dominant, with variability in expression. Sporadic mutations occur in $50 \%$ of patients. A gene was mapped on the long arm of chromosome 12 in $1994^{4}$. In 2001 the gene was identified as the PTPNII gene, accounting for approximately $50 \%$ of all cases ${ }^{5}$. Currently the diagnosis of NS remains mostly clinical. The main clinical features are characteristic facial features (hypertelorism, ptosis, down slanting palpebral fissures, low set posterior rotated ears and webbed neck), cardiac defects (most frequent pulmonary stenosis and hypertrophic cardiomyopathy; others are atrial septal defects, ventricular defects and coarctation of the aorta), chest deformity and growth retardation with short stature ${ }^{6,7}$.

Fifty to $70 \%$ of patients with NS have short stature $^{-3,8}$. Patients with NS have a typical growth pattern. Birth height and length are in the normal range, but patients fall below the $8^{\text {th }}$ percentile at 
approximately 3 months of age and remain growing below this percentile ${ }^{9,10}$. Onset of puberty is delayed, and bone maturation shows an average delay of 2 years. Ranke et al. and Witt et al.,10 recorded final heights from patients with NS. They reported mean heights of 162.5 and $161.0 \mathrm{~cm}$ in males and 152.7 and $150.5 \mathrm{~cm}$ in females, respectively. The underlying cause of short stature is unclear. Low insulin-like growth factor-I (IGF-I) levels have been reported ${ }^{11,12}$, as well as impaired spontaneous growth hormone $(\mathrm{GH})$ secretion ${ }^{11-14}$. $\mathrm{GH}$ stimulation tests are reported as normal ${ }^{13}$.

Studies with GH for patients with NS have been conducted in relatively small patient groups and found an increase in height velocity in the short term, with a waning effect in the longer term ${ }^{15-17}$. Data on final height are scarce. The effect of GH treatment on long-term growth and final height in larger groups of patients needs to be assessed.

We performed a retrospective study in 402 patients with NS treated with $\mathrm{GH}$, to evaluate the long-term effect and the gain in final height.

\section{PATIENTS AND METHODS}

All patients with a clinical diagnosis of NS who were enrolled in the KIGS International growth database from January 1985 until December 2004 were evaluated. Excluded were patients with insufficient reports on auxological details at the start of GH treatment. Auxological data (birth weight, birth height, height, height velocity, mid-parental height, weight, body mass index [BMI], GH dose and GH regimen), biochemical data (maximum growth hormone peak) and clinical data (age, sex, country of origin,'pubertal stage, adverse events) were collected. The total cohort consisted of 402 patients ( 242 male, 118 female) from 27 countries. Sixtythree percent of the patients originated from Europe, $17 \%$ from North America, 9\% from Australia and New Zealand, 1\% from South America and $10 \%$ from Asia.

Out of the total database of 402 patients, two sub-cohorts were formed: one cohort with patients who had 3 years of prepubertal follow-up, and one cohort with patients who reached near adult height on GH treatment. Three years was the longest representative period of prepubertal follow-up in this study group; after 3 years too many patients were lost to follow-up, mostly because of entering puberty.

Prepubertal follow-up was defined as yearly reports in patients without any signs of puberty. Puberty was defined as Tanner breast stage of at least 2 for girls ${ }^{18}$ and testis volume of at least $4 \mathrm{ml}$ for boys. If there were no reports on pubertal markers, patients were considered to be in puberty if they had a chronological age of at least 10 years for girls and at least 12 years for boys.

Near adult height was defined as height velocity less than $2 \mathrm{~cm}$ per year, based on intervals of at least 9 months (with minimum age above 15.0 years for girls and 17.0 years for boys). Chronological age at start of GH treatment was below 14.0 years for females and 16.0 years for males. At least 1 year of prepubertal GH treatment was required, and at least 4 years of $\mathrm{GH}$ treatment in total.

Reference growth curves were used from Tanner and Whitehouse ${ }^{18}$ for children with normal growth and from Ranke et al. ${ }^{9}$ for children with NS.

Recombinant GH was given as daily subcutaneous injections, with a median dose of $0.24 \mathrm{mg}$ / $\mathrm{kg} /$ week (range $0.17-0.77 \mathrm{mg} / \mathrm{kg} /$ week). Any adverse event occurring during $\mathrm{GH}$ treatment was reported by body system (musculo-skeletal, nervous, cardiovascular, respiratory, gastro-intestinal, metabolic and endocrine, hematological, urinary, reproductive and psychiatric).

Statistical analysis was by SAS and Windows XP Excel.

The study was reviewed and approved by an institutional ethics committee of the participating hospitals. Written informed consent was obtained from all patients and parents of patients involved in this study.

\section{RESULTS}

Baseline characteristics are shown in Table 1. Data from both sexes were pooled, since there were no significant differences between them.

Median birth weight and median birth length were -0.38 SDS and -0.69 SDS, respectively, according to Tanner standards. Mid-parental height was -0.41 SDS according to Tanner standards. The median maximal $\mathrm{GH}$ peak was $10 \mu \mathrm{g} / \mathrm{I}$ (measured 
TABLE 1

Baseline characteristics of the total cohort of patients with Noonan syndrome

\begin{tabular}{lcccc}
\hline & $\begin{array}{c}\mathbf{n} \\
(\text { total }=402)\end{array}$ & Median & 10 $^{\text {th }}$ percentile & $9^{\text {th }}$ percentile \\
\hline Gestational age (weeks) & 375 & 40.00 & 36.00 & 41.00 \\
Birth weight SDS & 366 & -0.38 & -2.13 & 1.01 \\
Birth length SDS & 243 & -0.69 & -2.55 & 1.40 \\
Midparental height SDS & 368 & -0.41 & -2.09 & 1.28 \\
Max. growth hormone peak $(\mu \mathrm{g} / \mathrm{l})$ & 298 & 10.00 & 4.60 & 28.00 \\
\hline
\end{tabular}

TABLE 2

Data at the start of growth hormone $(\mathrm{GH})$ therapy of the total cohort of patients with Noonan syndrome

\begin{tabular}{lcccc}
\hline & $\begin{array}{c}\mathbf{n} \\
(\text { tota } \mathbf{l}=402)\end{array}$ & Median & $\mathbf{1 0}^{\text {th }}$ percentile & $\mathbf{9 0}^{\text {th }}$ percentile \\
\hline Chronological age (yr) & 402 & 9.73 & 4.59 & 14.38 \\
Bone age (yr) & 109 & 7.30 & 2.25 & 11.90 \\
Height SDS & 402 & -2.95 & -4.29 & -1.94 \\
Height velocity (cm/yr) & 182 & 4.39 & 2.89 & 6.45 \\
Height - MPH SDS & 368 & -2.54 & -4.53 & -0.77 \\
Weight SDS & 402 & -2.61 & -4.13 & -1.17 \\
BMI SDS & 402 & -0.50 & -1.87 & 1.00 \\
Dose of GH (mg/kg/week) & 402 & 0.24 & 0.16 & 0.36 \\
Frequency of injections & 402 & 7.00 & 6.00 & 7.00 \\
\hline
\end{tabular}

MPH = mid-parental height; $\mathbf{B M I}=$ body mass index.

in 298 patients) and only a minority of patients had a stimulated $\mathrm{GH}$ value in the deficient range.

Data at start of GH treatment for all 402 patients are shown in Table 2.

Three year longitudinal prepubertal follow-up was available in 73 patients. Baseline characteristics and background data at the start of $\mathrm{GH}$ treatment and in the first and second year of followup were not statistically different from the total cohort. Median age at start was 7.73 years, median height was -2.86 SDS according to Tanner standards, and -1.04 SDS according to Noonan standards, median weight was -2.20 SDS, with a median BMI of -0.62 SDS. Height velocity, height SDS and bone age advancement during three years of GH therapy are shown in Figures 1-3. Height velocity almost doubled in the first year, declined after 2 and 3 years, but remained approximately 1 $\mathrm{cm} /$ year higher after 3 years than at the start of treatment.

Height SDS increased by 0.76 SDS, with most gain during the first year and a smaller but constant gain during the second and third years of $\mathrm{GH}$ therapy. The increase according to Noonan stan- 


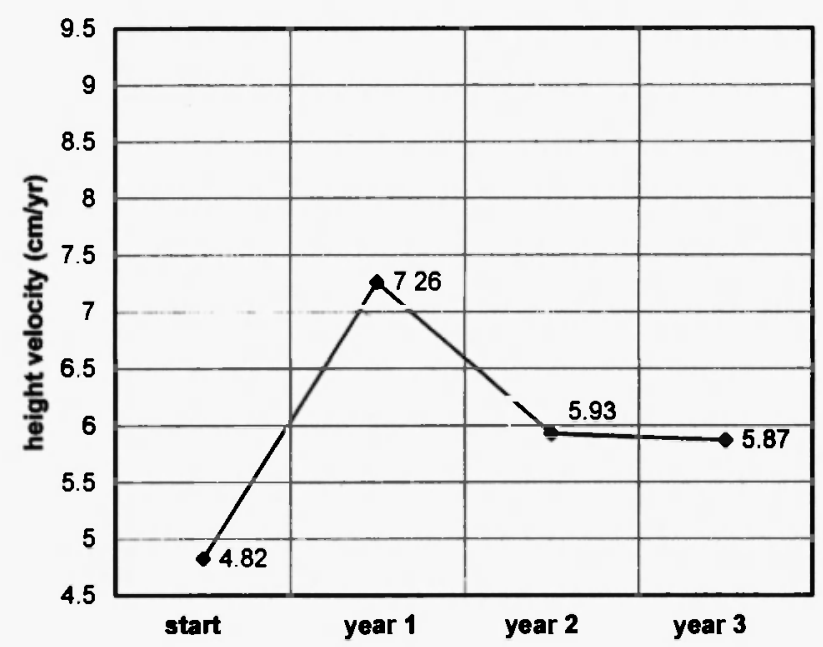

Fig. 1: Height velocity during 3 years of growth hormone treatment in patients with Noonan syndrome.

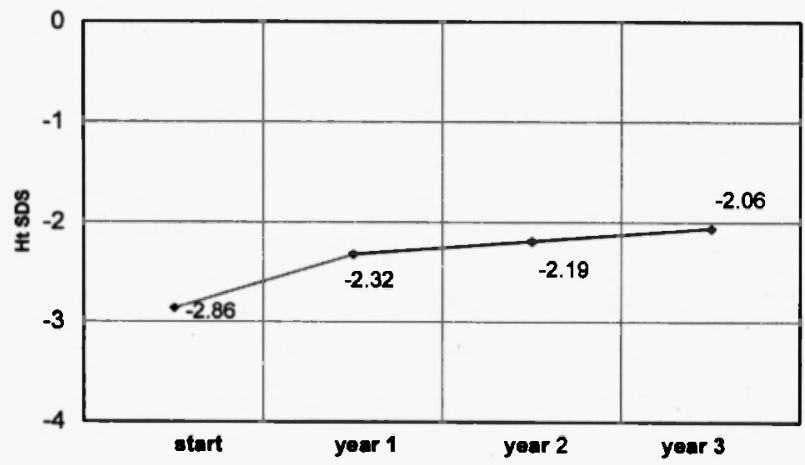

Fig. 2: Height standard deviation score (Ht SDS) during 3 years of growth hormone treatment in patients with Noonan syndrome.

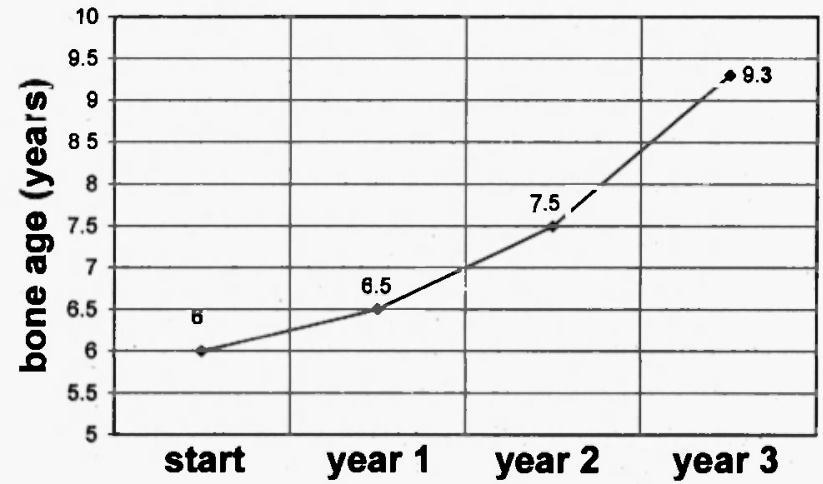

Fig. 3: Bone age advancement during 3 years of growth hormone treatment in patients with Noonan syndrome.

dards during the first, second and third year was $0.53,0.22$ and 0.15 , respectively. The total increase in height SDS according to Noonan standards after 3 years was 0.81 SDS. Bone age increased from a median of 6.0 years at the start to a median of 9.3 years after 3 years of $\mathrm{GH}$ treatment.

Near adult height after at least four years of GH treatment was reached in 24 patients. Baseline characteristics and background data were not significantly different from the total cohort. Median age at start of GH treatment was 10.17 years, with a median height SDS of -3.24 . Median duration of GH treatment was 7.59 years. The gain in height SDS per patient is shown in Figure 4. Median gain in height SDS according to Tanner standards was

\section{patient number}

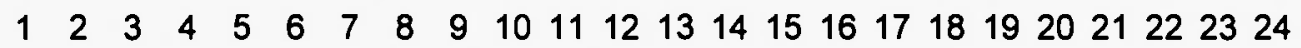

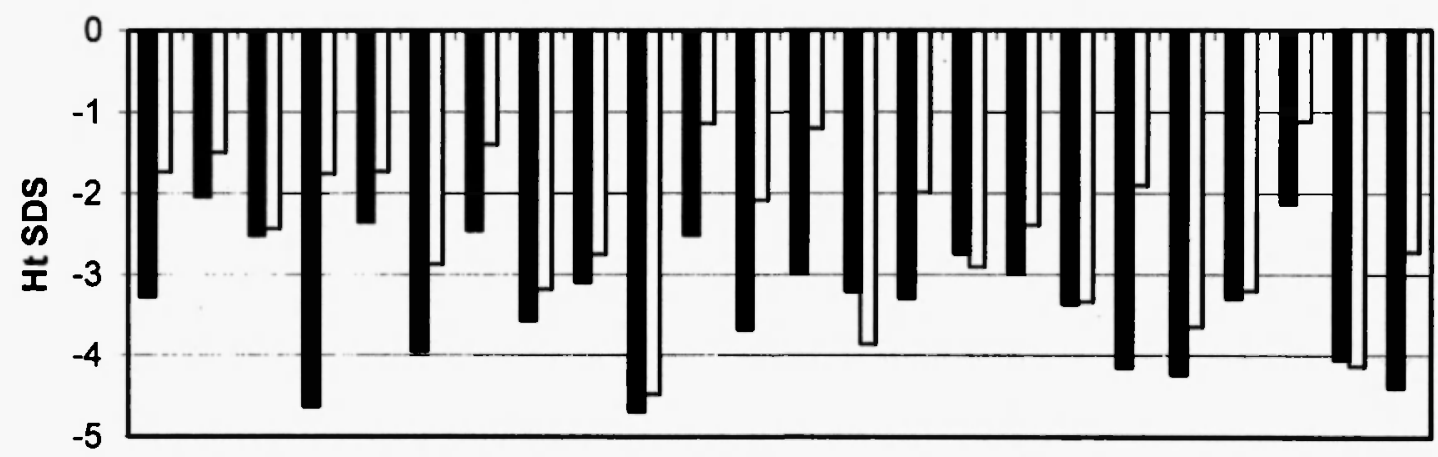

Fig. 4: Height standard deviation score (Ht SDS) at start of growth hormone treatment (black bars) and at near adult height (white bars) in patients with Noonan syndrome. 
0.61 . Thirteen of the 24 patients (54\%) had a final height below -2 SDS (Tanner standards), compared to 23 of the 24 patients $(96 \%)$ at the start of $\mathrm{GH}$ treatment. Median gain in height SDS according to Noonan standards was 0.97 SDS. Bone age advanced from a median of 7.0 years (delay 3.17 years) to a median of 15.7 years (delay 2.74 years).

No serious adverse events in relation to $\mathrm{GH}$ treatment were observed.

One hundred and twenty eight patients discontinued $\mathrm{GH}$ treatment before reaching final height $(31.8 \%)$. The main reasons mentioned are shown in Table 3. The group who discontinued treatment had a smaller response in height SDS after 1 year than the group that was treated for 3 years (mean 0.42 vs 0.53 , median 0.42 versus 0.42 ), but this was not statistically significant.

\section{DISCUSSION}

This study provides an analysis of long-term $\mathrm{GH}$ treatment in a large group of patients with NS. There was a median gain in final height of 0.61 SDS according to Tanner standards and 0.97 SDS according to Noonan standards. Thus there was a significant but relatively small increase in final height. More than $50 \%$ of the patients reached a final height above -2 SDS (Tanner), whereas more than $95 \%$ of patients had a height below -2 SDS at the start of treatment. In our opinion, it is an important result in this lower height range for patients to achieve a final height above -2 SDS, within the socially accepted 'normal' range.

NS remains a clinical diagnosis, and thus making the correct diagnosis depends on the individual observer. The development of scoring systems $s^{8,19,20}$ partly solves this problem, but establishing the correct diagnosis remains a limitation in studies on patients with NS. However, we assume that the diagnosis was made correctly in our study, because it was made by experts on the basis of clinical characteristics. In addition, Turner's syndrome was excluded by chromosomal analysis.

The auxological data of our study group at birth were slightly below normal, which reflects the data reported in the literature, but the median height at start of treatment is in the lower height range for patients with NS. Presumably our study group
TABLE 3

Discontinued patients: reasons for discontinuation

\begin{tabular}{lc}
\hline Reason for discontinuation & $\mathbf{n}$ (total = 128) \\
\hline Poor response & 31 \\
Parents' decision & 10 \\
Lost to follow up & 10 \\
Non-compliance & 12 \\
Normal height reached & 6 \\
Other & 59 \\
\hline
\end{tabular}

represents a pre-selection of short patients with NS, because these patients are more likely to be referred for $\mathrm{GH}$ treatment. The parents of the patients are also relatively short. This may partly reflect the fact that there would be some parents with NS, and the selection bias for $\mathrm{GH}$ treatment, which may reflect the inheritance of short stature due to other causes from the patients' parents.

There were more male patients than female patients in the study group. The male preponderance might reflect male preferential inheritance ${ }^{21}$, or less acceptance of short height in boys ${ }^{22}$. The drop-out proportion in this study was $31.8 \%$. We observed a smaller response in the first year in the drop-out group compared to the long-term treatment group. Therefore, the long-term effect of $\mathrm{GH}$ we have reported may be a slight overestimation of the benefit of treatment for the total group.

Previous GH studies conducted in patients with NS are scarce and performed with relatively low numbers of patients. The gain in height SDS after treatment with $\mathrm{GH}$ is significant in the short term, but the observed effects are variable in the long term. De Schepper et al. ${ }^{15}$ treated 23 prepubertal patients with recombinant human $\mathrm{GH}$ at a dose of $0.35 \mathrm{mg} / \mathrm{kg} /$ week for 1 year. They found a mean increase in growth velocity of $4.0 \mathrm{~cm} / \mathrm{yr}$, and an increment in height SDS of 0.53 , without acceleration of bone maturation. In patients treated with $\mathrm{GH}$ for 3 years, Noordam et al. ${ }^{17}$ found acceleration in bone maturation: 1.2 year/year versus 0.5 year per year in a control group. Gain in final height seemed to be compromised by this accelerating effect, with 
a mean gain in height SDS corrected for bone age of only 0.3 . The only larger study, performed by Kirk et al. ${ }^{16}$ in 66 patients, found a mean increment in height SDS of 0.6 in 3 years. In the ten patients in the study by Kirk et al. who reached near final height, the authors did not find a substantial improvement in final height, but duration of $\mathrm{GH}$ treatment was shorter compared to our study group ( 5.15 years versus 7.59 years). In the current study $\mathrm{GH}$ dosage was relatively low so the effect on final height would probably be better with a higher dosage, as used in the follow-up study by Noordam et al. ${ }^{17}$.

The benefits of $\mathrm{GH}$ treatment need to be measured against the burden of $\mathrm{GH}$ treatment. In our study no serious adverse events in relation to $\mathrm{GH}$ were reported. The reasons for discontinuation partly reflect the practical burden of $\mathrm{GH}$ treatment (non-compliance, problems with injections), as well as the high costs of $\mathrm{GH}$ treatment. The high costs of GH therapy have to be carefully counterbalanced against the gain in height. Lee et al. estimated the potential cost of GH therapy to be around 52,000 dollars per $2.54 \mathrm{~cm}$ of gain in height ${ }^{22}$. Although the estimate in that article was based on patients with idiopathic short stature, it gives an indication. The patients in the lower height range may benefit most from $\mathrm{GH}$ treatment, because with a relatively small gain in final height they still reach a socially more acceptable final height. The balance between the - significant but small - gain in height and the burden and costs of treatment needs to be considered in every patient.

\section{CONCLUSIONS}

In this study we found an early response to $\mathrm{GH}$ treatment with a waning effect thereafter. However, after 3 years of GH treatment there is still a gain in height SDS and at near adult height the gain was 0.61 SDS and 0.97 SDS, according to Tanner standards and Noonan standards, respectively. More than $50 \%$ of patients reached a final height above -2 SDS according to Tanner standards.

GH treatment is effective in NS without adverse side effects but the benefit and burden of treatment need to be considered when counselling patients about potential GH therapy in this condition.

\section{ACKNOWLEDGEMENTS}

We would like to thank all our collaborators for their co-operation and perseverance. By reporting their data and maintaining the KIGS database they have made this study possible.

BJO has no financial or other relationship that might lead to a conflict of interest. GK is a fulltime employee of Pfizer.

This study was supported by Pfizer Inc.

\section{REFERENCES}

1. Noonan JA, Ehmke DA. Associated noncardiac malformations in children with congenital heart disease. J Pediatr 1963; 468-469.

2. Mendez HM, Opitz JM. Noonan syndrome: a review. Am J Med Genet 1985; 21: 493-506.

3. Nora JJ, Nora AH, Sinha AK, Spangler RD, Lubs HA The Ullrich-Noonan syndrome (Turner phenotype). Am J Dis Child 1974; 127: 48-55.

4. Jamieson CR, van der Burgt I, Brady AF, van Reen M, Elsawi MM, Hol F, Jeffery S, Patton MA, Mariman E. Mapping a gene for Noonan syndrome to the long arm of chromosome 12 . Nat Genet 1994; 8: 357-360.

5. Tartaglia M, Mehler EL, Goldberg R, Zampino $G$, Brunner HG, Kremer $\mathrm{H}$, van der Burgt I, Crosby $\mathbf{A H}$, Ion A, Jeffery S, Kalidas K, Patton MA, Kucherlapati RS, Gelb BD. Mutations in PTPN11, encoding the protein tyrosine phosphatase SHP-2, cause Noonan syndrome. Nat Genet 2001; 29: 465-468.

6. Noonan JA. Noonan syndrome. An update and review for the primary pediatrician. Clin Pediatr (Phila) 1994; 33: 548-555.

7. Noordam C, Thoonen G, van der Burgt CJ. [The Noonan syndrome from a pediatric perspective]. Ned Tijdschr Geneeskd 2003; 147: 644-648.

8. Sharland M, Burch M, McKenna WM, Paton MA. A clinical study of Noonan syndrome. Arch Dis Child 1992; 67: 178-183.

9. Ranke MB, Heidemann $P$, Knupfer C, Enders $H$, Schmaltz AA, Bierich JR. Noonan syndrome: growth and clinical manifestations in 144 cases. Eur J Pediatr 1988; 148: 220-227.

10. Witt DR, Keena BA, Hall JG, Allanson JE. Growth curves for height in Noonan syndrome. Clin Genet 1986; 30: 150-153.

11. Spadoni GL, Bernardini S, Cianfarani S. Spontaneous growth hormone secretion in Noonan's syndrome. Acta Paediatr Scand 1990; 367: 157.

12. Ahmed ML, Foot ABM, Edge JA, Lamkin VA, Savage MO, Dunger DB. Noonan's syndrome: abnormalities of the growth hormone/IGF-1 axis and the response to treatment with human biosynthetic growth hormone. 
Acta Paediatr Scand 1991; 90: 446-450.

13. Noordam C, van der Burgt I, Sweep CG, Delemarrevan de Waal HA, Sengers RC, Otten BJ. Growth hormone $(\mathrm{GH})$ secretion in children with Noonan syndrome: frequently abnormal without consequences for growth or response to GH treatment. Clin Endocrinol (Oxf) 2001; 54: 53-59.

14. Tanaka K, Sato A, Naito $T$, Kuramochi K, Itabashi $H$, Takemura $Y$. Noonan syndrome presenting growth hormone neurosecretory dysfunction. Intern Med 1992; 31: 908-911.

15. De Schepper J, Otten BJ, François I, Bourguignon JP, Craen M, Van der Burgt I, Massa GG. Growth hormone therapy in pre-pubertal children with Noonan syndrome: first year growth response and comparison with Turner syndrome. Acta Paediatr 1997; 86: 943-946.

16. Kirk JM, Betts PR, Butler GE, Donaldson MD, Dunger DB, Johnston DI, Kelnar CJ, Price DA, Wilton P, Group tU. Short stature in Noonan syndrome: response to growth hormone therapy. Arch Dis Child 2001; 84: 440-443.

17. Noordam C, van der Burgt I, Sengers RC, Delemarrevan de Waal HA, Otten BJ. Growth hormone treatment in children with Noonan's syndrome: four year results of a partly controlled trial. Acta Paediatr 2001; 90: 889-894.

18. Tanner JM, Whitehouse RH, Takaishi M. Standards from birth to maturity for height, weight, height velocity, and weight velocity: British children, 1965. II. Arch Dis Child 1966; 41: 613-635.

19. Duncan WJ, Fowler RS, Farkas LG, Ross RB, Wright AW, Bloom KR, Huot DJ, Sondheimer HM, Rowe RD. A comprehensive scoring system for evaluating Noonan syndrome. Am J Med Genet 1981; 10: 37-50.

20. van der Burgt I, Berends $E$, Lommen $E$, van Beersum $S$, Hamel B, Mariman E. Clinical and molecular studies in a large Dutch family with Noonan syndrome. Am J Med Genet 1994; 53: 187-191.

21. Tartaglia M, Cordeddu V, Chang H, Shaw A, Kalidas K, Crosby A, Patton MA, Sorcini M, van der Burgt I, Jeffery S, Gelb BD. Paternal germline origin and sexratio distortion in transmission of 'PTPNII mutations in Noonan syndrome. Am J Hum Genet 2004; 75: 492 497.

22. Otten BJ, Noordam C. Short stature in Noonan syndrome: demography and response to growth hormone treatment in KIGS. In: Ranke MB, Gunnarson R, eds. Growth Hormone Therapy in KIGS: 10 Years Experience. Mannheim: J\&J Verlag, 1999.

23. Lee JM, Davis MM, Clark SJ, Hofer TP, Kemper AR. Estimated cost-effectiveness of growth hormone therapy for idiopathic short stature. Arch Pediatr Adolesc Med 2006; 160: 263-269. 
Brought to you by | Radboud University Nijmegen (Radboud University Nijmegen) Authenticated | 172.16.1.226

Download Date | 7/13/12 12:22 PM 